\title{
Eric Schwitzgebel: Perplexities of Consciousness
}

Alsmith, Adrian John Tetteh

Published in:

Phenomenology and the Cognitive Sciences

DOI:

10.1007/s11097-013-9315-1

Publication date:

2014

Document version

Publisher's PDF, also known as Version of record

Citation for published version (APA):

Alsmith, A. J. T. (2014). Eric Schwitzgebel: Perplexities of Consciousness. Phenomenology and the Cognitive Sciences, 13(3), 497-501. https://doi.org/10.1007/s11097-013-9315-1 


\title{
Eric Schwitzgebel: Perplexities of consciousness \\ MIT Press, Cambridge MA, 2011, 240 pp., ISBN: 9780262014908, Hardcover: \$27.95/£19.95
}

\author{
Adrian Alsmith
}

(C) Springer Science+Business Media Dordrecht 2013

A glance at the contents of this book might be enough to persuade that it is absolutely required reading for anyone interested in the study of consciousness. The discussion is replete with insight into a number of neglected topics: colour in dream experience (chapter 1), echolocation in auditory experience (chapter 4) and closed-eye visualisations (chapter 8). More familiar themes such as the spatial qualities presented in visual experience (chapter 2), visual imagery (chapter 3), the introspectionist movement (chapter 5), conscious attention and multisensory experience (chapter 6) are given genuinely novel treatment. Chapter 7, titled 'The Unreliability of Introspection' is almost a microcosm of the book as a whole; it is not quite representative of the entire book but it gives a strong flavour of the style of argument employed elsewhere, so the half-interested (or hurried) reader would be well advised to take it in as a taster. The book is written in accessible prose suitable for an interested, non-professional audience. But those working in the philosophy and/or psychology of perception and/or phenomenologically orientated philosophy of mind and/or cognitive science certainly ought to take note.

Perplexities of consciousness is a fun read, in a conversational style. Themes and issues arise and return more in the manner of an evening's discussion than a conventional, impersonal academic exposition. As a consequence, though, the reader might occasionally yearn for more precise expression than they find in its pages. Schwitzgebel notes his reticence about complex argument early on, in the Preface. Still, some might nevertheless be slightly disconcerted in the way that he ploughs on without taking the necessary (probably boring) few pages to clarify central notions.

But there is a sense in which that is fine. His aim is not to systematically demolish a clearly articulated theory, nor is it to develop a more robust theory in its stead. Rather his aim is to motivate a large, but healthy degree of doubt concerning the following questions: How much do individuals know about their experience? And how much do you know about your own? The dearth of attempts to engage with

\footnotetext{
A. Alsmith $(\bowtie)$

Centre for Subjectivity Research, School of Humanities, University of Copenhagen,

Njalsgade 140-142, 5th floor, 2300 Copenhagen S, Denmark

e-mail: adrianjtalsmith@gmail.com
} 
either of these questions is something of a scandal, especially since so much of the contemporary, and indeed, historical study of the mind rests upon roughly the following answer to both questions: Rather a lot. Schwitzgebel hopes that by the time you are done with his book, or perhaps even only a few chapters, you might begin to suspect a touch of hubris in such an answer.

The two questions (or rather, the two claims that form Schwitzgebel's answers) are intertwined throughout the text. Schwitzgebel puts his "scholarly emphasis" on the first when he claims "that people in general know very little about what might seem to be obvious features of their stream of conscious experience" (p. ix). ${ }^{1}$ But clearly his aim is to persuade the reader of this claim by feeling the force of his worries personally; he wants "to persuade you [the reader] that you yourself know very little about such matters" (ibid.). Schwitzgebel wants to rock your world. As a consequence, the fate of the general claim is often rhetorically entangled with a host of invitations to commit to a stance on one's own experience.

These invitations are typically interspersed with snippets of autobiographical narrative detailing Schwitzgebel's attempts to probe his own experience. Frequently, these passages and the ensuing bafflements are delivered with humour, but they are always sincere. They serve an essential function in the book's style of argument, as Schwitzgebel evidently hopes that the reader will find that they have similar difficulty in answering his seemingly simple query, a difficulty which he hopes will blossom into the full frustration of uncertainty. But what do we infer from that? Schwitzgebel's immediate inference, of course, is to the claim that "you yourself know very little" about the matter at hand. But even if we grant this - or admit, at least, that one's uncertainty makes the suggestion of some degree of ignorance more plausible - that is not enough for Schwitzgebel. For merely engendering uncertainty in his reader does not establish the ignorance of people in general.

In a representative passage from the end of chapter 3, he writes:

“...it isn't entirely obvious how vivid and detailed my visual imagery is [...] I feel in myself, and I think you may feel in yourself, the potential for error [...] I find the introspection of visual imagery difficult, if I set about it conscientiously. Thus, I don't think we should be surprised if people - including, perhaps, you and me — can go badly awry" (p. 55)

Now, even if Schwitzgebel has us convinced about our own case (and/or we believe his account of his) why should we think the same of others? In the rest of this review, I will argue that what does much of the work here is the assumption that people likely do not differ, in relevant ways (a qualification which I will drop hereafter), in respect of their experiences (e.g., of imagery in a given task). Call this assumption invariance. Invariance implicitly pervades the text. Moreover, noting it reveals that Schwitzgebel's considered view is not as radical as it might seem.

To draw invariance out fully, we need to make a distinction between the variability of experiences and the variability of introspective judgements about experiences. The two are not distinguished, for instance, when Schwitzgebel engages with what he calls a "variability-endorsing-optimist" (p. 134, see also pp. 67-68), an imagined interlocutor who, when presented with significant variation in introspective

${ }^{1}$ All page references will be to Schwitzgebel (2011) 
judgements, holds that "these judgments are all largely correct" (p. 133) and thus that "people must differ immensely in the structure of their conscious experience" (ibid.). But people could differ immensely in the structure of their experience whether or not they were reliable judges of their experience.

Note that if this really were the case, many parts of Schwitzgebel's discussion would simply be undermined. To pick examples from the beginning and the end of the book (there are many more in between): It is no wonder that a "fundamental fact" about colour experience in dreams seems to elude Schwitzgebel (p. 15) if there is no such fact to be found. For the same reason, it is no wonder that the question of what people "typically experience when their eyes are closed" admits of several different answers (p. 155).

That Schwitzgebel rejects such a view indicates that he sincerely believes that there is some general fact of the matter in each of his discussions, some appropriate generalisation towards which each discussion might gravitate. Despite his occasional flirtation with relativistic ideas (e.g., p. 18), far from being a sceptic, Schwitzgebel is rather optimistic about the possibility of finding a description that accurately captures what we all experience in a given situation.

Schwitzgebel's optimism in this sense, his endorsement of invariance, is actually built into his favoured styles of argument. At the outset, he usefully lists three argument types that recur throughout the book. The first of these, the argument from variation, clearly has the aforementioned assumption built into its structure. As Schwitzgebel puts it: "People often differ greatly in their judgments about their stream of experience $[\ldots]$ it seems unlikely that their actual underlying experiences vary correspondingly. Consequently, some of their judgments - we don't necessarily know which ones - are probably wrong" (p. xi) The argument from variation moves from particular cases of conflicting judgements about certain general types of experience to the conclusion that any such judgement is likely in error. We cannot necessarily determine which judgement is in error, so all such judgements are equally suspect and our confidence in any given judgement should be low. For the argument from variation to validly reach such a general conclusion, it is required that it is likely that people do not exhibit variation in certain respects, i.e. that their experiences are not significantly different.

A similar point holds for the other two argument types: The argument from error moves from particular cases of error to the general conclusion that "reflection, in such cases, is therefore prone to error" (ibid). But to establish particular cases of error requires that there are two or more judgements with the same truth conditions, and that requires (inter alia) that the experiences of which one judges do not vary between these judgements. The third argument type is one that we have encountered already: the argument from uncertainty. As stated above, if we are to think that our uncertainty "suggests a substantial possibility of error in judgments of that general type" (ibid.) then it had better be true that the experiences that those judgments concern do not vary.

The key point here is that Schwitzgebel cannot be a sceptic (or at least, a pessimist) about the possibility of giving correct general descriptions of experiences, if he also hopes to validly employ his sceptical arguments about judgements concerning those experiences. For even if I believe that my judgement might fail to accurately describe my own experience, the same possibility for error can only apply to another 
judgement if it has the same truth conditions. And if the experiences in question are significantly different, then judgements concerning those experiences cannot have the same truth conditions.

So what is the likelihood that there are intraindividual, interindividual or indeed intergroup differences in the kinds of experiences that Schwitzgebel discusses? I think it is plausible that there is greater likelihood in some cases than in others. Does the breadth and determinacy of my visual field differ much from yours? Probably not. Is your mental imagery as detailed as mine? Well, maybe. Do you have a significantly different experience than I do when thinking "Claret is delightful"? I am not so sure. Do you and I both have auditory experience of the location and properties of silent objects around us? Pardon me... what?

This last is one of Schwitzgebel's more exotic examples, discussed in chapter 4, in which his aim is to convince the reader of the possibility that they have an experience (of echolocation) that they did not otherwise believe that they did. He suggests that when we try, for instance, locating a moving hand (ideally not our own) in front of our face or walking towards a wall and judging when to stop before hitting it, we are rather better at perceiving objects by echolocation than we might have thought. The crucial question is this: even if I were convinced that echolocation is something that I can experience when given the right instructions, why should I extrapolate from that to my auditory experience in general or indeed that of others? Just because you or I might be able to use and access this information at some times, it does not necessarily follow that either of us experience things in this way at all times. Schwitzgebel argues that the inference is at least plausible given that there are instances in which we notice an unexpected change in our surroundings, e.g. an unexpected chair in a tiled hallway, on the basis of some change in how things sound. But again, the inference can be challenged. Noticing a discrepancy is hardly incontrovertible evidence for us experiencing something in the absence of any discrepancy.

If one did not bear the distinction between the variability of experiences and introspective judgements in mind, one might find it a little incongruent that Schwitzgebel makes a positive case for the presence of echolation properties in our perceptual experience. Sure enough, at the end of the chapter, Schwitzgebel qualifies his remarks by affirming that here too his ability to judge of his own experience is not to be trusted. Invariance is never in doubt, though. If what I say above is correct, then (by Schwitzgebel's own lights) it is important that he might still be right about his own auditory experience, even if he cannot reliably tell if he is so by introspection. Similarly, even if we cannot reliably tell what our experience is like, if invariance is true then we can at least be optimistic that there is some general fact about our experience that we are all prone to getting right or wrong.

Invariance manifests a certain degree of respect for the distinction between metaphysics and epistemology. Schwitzgebel's concern is with our epistemic relation to our experiences, rather than metaphysically appropriate generalisations about our experiences. But viewed from another angle, what is clear in this case is that Schwitzgebel must lean fairly heavily on a metaphysical claim (viz. invariance) in order to run his epistemically weakening sceptical arguments. Upon reading the 
following (slightly butchered) passage from the preface, one might wonder whether Schwitzgebel has licence to such a metaphysical claim:

"Something apparently preposterous, it seems, must be true of consciousness [...] Furthermore, we appear to have no solid basis for choosing among the various metaphysical alternatives: Armchair philosophical reflection leaves us only idiosyncratic hunches about equally unsupported half-intuitive theories, while empirical observation of physical structure and behavior is uninterpretable [...] without a prior theory of consciousness, creating a tight vicious circle." (p. x; see also pp. 112-116)

Might some of the apparently preposterous facts about consciousness lead us to deny invariance? It would be misleading to say that the jury is still out on this one; on the assessment of intraindividual differences, the most basic challenge to invariance, the jury has yet to be assembled.

Still, even if Schwitzgebel is guilty of holding that something not apparently preposterous (invariance) is true of consciousness, this slight tension in his overall treatment ought not to affect the way his individual arguments are received. For these arguments apply to all and any who believe that we can generally get things right (or wrong) about consciousness; I believe that includes most people studying consciousness today.

\section{Reference}

Schwitzgebel, E. (2011). Perplexities of consciousness. Cambridge: MIT Press. 